\title{
Development and validation of a scale for assessing reasons for substance use in schizophrenia: The ReSUS scale
}

\author{
Lynsey Gregg* , Christine Barrowclough, Gillian Haddock \\ Division of Clinical Psychology, School of Psychological Sciences, University of Manchester, United Kingdom
}

\section{A R T I C L E I N F O}

Keywords:

Schizophrenia

Substance use

Dual diagnosis

Comorbidity

Questionnaire

\begin{abstract}
A B S T R A C T
This paper reports on the development of a questionnaire to assess self reported reasons for substance use in schizophrenia: the 'reasons for substance use in schizophrenia' (ReSUS) scale and explores the relationship between reasons for use, psychiatric symptoms and substance use in a sample of 230 people with psychosis. Principal components analysis revealed three subscales: "coping with distressing emotions and symptoms', "social enhancement and intoxication" and "individual enhancement". Predicted associations were partially supported. 'Coping' reasons for use were related to positive symptoms, general symptoms, global functioning, depression and suicide behaviour as well as substance use (quantity of use and problems related to use). 'Individual enhancement' reasons were related to positive symptoms, to global functioning and to negative consequences of substance use. 'Social enhancement and intoxication' reasons were related to negative consequences of use but not to psychopathology. The findings suggest that the ReSUS is a reliable and valid instrument which can be used to explore self reported reasons for substance use and their relationship to psychotic symptoms in people with schizophrenia and other psychotic disorders.
\end{abstract}

(C) 2009 Elsevier Ltd. All rights reserved.

\section{Introduction}

Around half of all people with a diagnosis of schizophrenia use drugs or alcohol (Regier et al., 1990). This comorbidity has been associated with a range of adverse clinical and social outcomes including more positive symptoms (Pencer \& Addington, 2003), more relapses and hospitalizations (Linszen, Dingemans, \& Lenior, 1994), increased aggression and violence (Cuffel, Shumway, Choulgian, \& MacDonald, 1994) and higher rates of homelessness and housing instability (Drake, Osher, \& Wallach, 1991). Significantly, these adverse outcomes occur at lower levels of intake in people with schizophrenia than in the general community (Drake, Osher, \& Wallach, 1989). A better understanding of the reasons why people with schizophrenia use drugs and alcohol is essential if effective interventions aimed at reducing that use are to be developed.

People with a diagnosis of schizophrenia who also use drugs and alcohol report using substances for many different reasons. Research in this area has consistently shown that drugs and alcohol are used for many of the same reasons that people in the general population use them for: to increase pleasure, to fit in with others and to alleviate negative affective states such as boredom and depression (Addington \& Duchak, 1997; Baker et al., 2002; Dixon, Haas, Weiden, \& Frances, 1991; Fowler, Carr, Carter, \& Lewin, 1998; Gearon, Bellack, Rachbeisel,

\footnotetext{
* Corresponding author. Division of Clinical Psychology, School of Psychological Sciences, University of Manchester, Zochonis Building, Brunswick Street, Manchester, M13 9PL, United Kingdom. Tel.: +44 161275 8488; fax: +44 1612758487.

E-mail address: lynsey.gregg@manchester.ac.uk (L. Gregg).
}

\& Dixon, 2001; Goswami, Mattoo, Basu, \& Singh, 2004; Green, Kavanagh, \& Young, 2004; Schofield et al., 2006; Spencer, Castle, \& Michie, 2002). There is less consensus about whether people use substances for reasons directly related to schizophrenia however (as suggested by Khantzian, 1985, 1997), either in terms of psychotic symptoms, the distress associated with those symptoms or the side effects of neuroleptic medication. Only a handful of studies have reported that people experiencing psychosis report using substances to self medicate (Addington \& Duchak, 1997; Gearon, Bellack, Rachbeisel, \& Dixon, 2001; Goswami, Mattoo, Basu, \& Singh, 2004; Spencer, Castle, \& Michie, 2002) but because of sampling and methodological differences (in the way that dual diagnosis was defined; the diagnostic criteria used for substance use and the variety of measures to assess reasons for use) it is difficult to draw firm conclusions about these results.

In an attempt to address some of the methodological limitations of the earlier self report studies Gregg, Haddock and Barrowclough (2009) used Q methodology (Stephenson, 1953) to examine reasons for use by people with a diagnosis of schizophrenia and current comorbid substance use. $Q$ methodology requires participants to sort statements (in this case reasons for use) by placing them on a structured response grid (the $Q$ grid, See Fig. 1 ). $Q$ sorts are then analysed using a form of factor analysis in which each person's sort is correlated with all of the other sorts. The resultant factors consist of clusters of individuals who sorted statements in similar ways. Three sub groups of substance users were identified from the $Q$ sorts: one group used drugs or alcohol primarily for enhancement purposes: to relax and to have a good time with others; to feel good and to celebrate. They 


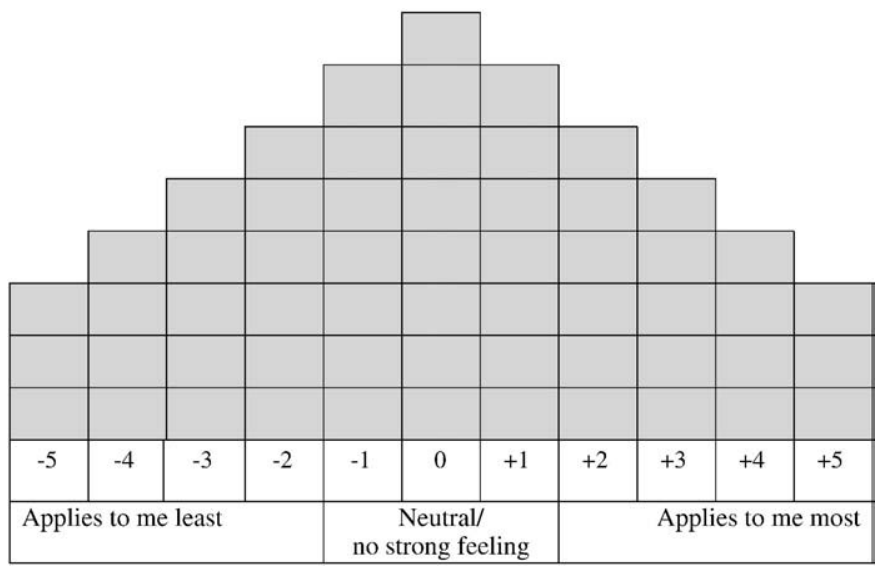

Fig. 1. $Q$ sort response grid.

endorsed the social aspects of substance use and used them to conform to their peer group, drinking alcohol or using drugs to fit in and when they felt under pressure from others. A second group used substances for 'self improvement' purposes and to intensify their experiences. They used drugs and alcohol in order to feel more creative, self aware, motivated and confident. The final group used drugs and alcohol to regulate negative affect and to alleviate or cope with the positive symptoms of schizophrenia: they used when they were feeling depressed, stressed, anxious, lonely and bored and when they were experiencing unpleasant thoughts; feeling suspicious or paranoid or were hearing voices. More than a third of the sample overall reported using substances when they were feeling paranoid or were hearing voices, providing some support for Khantzian's (1985, 1997) self medication hypothesis.

It is possible that different determinants of substance use may be related to distinct patterns of alcohol and drug consumption, to symptom severity and to motivation to change. There is already some evidence to suggest that this is the case e.g. Spencer, Castle, and Michie (2002) found that 'coping with unpleasant affect' motives significantly predicted quantity of recent use, problems related to that use and readiness to change in a sample of 69 patients with psychotic disorders. They also found that 'enhancement' motives predicted levels of recent use and 'relief of positive symptoms and medication side effects' motives predicted substance use dependence. Spencer, Castle, and Michie (2002) also found that 'total motives' (the sum of the five motive subscales they reported) were predicted by both negative symptoms and by global symptom severity scores (assessed using the Brief Symptom Inventory). However they did not assess the impact of symptoms on individual motive subscales. Likewise Gregg, Haddock, and Barrowclough (2009) did not assess current psychiatric symptoms and were therefore not able to examine the links between the three substance use profiles they identified and current psychiatric symptomatology. Additionally, few studies have examined reasons for use in the context of the known demographic risk factors such as age, gender and socioeconomic status. Gregg, Haddock, and Barrowclough (2009) found that the women in their sample were more likely to be using substances for 'coping' reasons than men but this has not been reported elsewhere.

Further research is necessary to explore the extent to which different reasons for use are related to demographic variables, to patient symptomatology, different patterns of substance use and to motivation to change. If relationships between these variables are confirmed, this could potentially have significant treatment implications.

The aim of the current study was to explore these relationships in a large sample of people diagnosed with schizophrenia or another psychotic disorder who also met criteria for current alcohol or substance abuse or dependence. Because the $Q$ sort procedure used by Gregg, Haddock, and Barrowclough (2009) can take 30-60 min to administer its usefulness in a research context when administered as part of a battery of assessments is limited. We therefore developed a new questionnaire measure: the 'reasons for substance use in schizophrenia' (ReSUS) scale using some of the items from Gregg, Haddock, and Barrowclough's (2009) Q methodology study and present the psychometric properties of this new questionnaire here. We examined whether the subscales of the ReSUS were related to demographic variables, psychopathology, current levels of substance use, consequences of use and readiness to change. We hypothesised that:

a) The ReSUS scale would be a valid and reliable measure for assessing reasons for use in people with schizophrenia and other psychotic disorders

b) The ReSUS subscales would be similar to those identified by Gregg, Haddock, and Barrowclough (2009)

c) Reasons for use would be related to gender, with females being more likely to use substances for 'coping' reasons for use than males

d) Reasons for use would be related to both quantity of substance use, with higher scores on the ReSUS subscales being associated with higher quantities of use, and problems associated with substance use, with higher ReSUS scores being associated with more self reported negative consequences

e) Reasons for use would be related to psychiatric symptomatology with higher ReSUS scores being associated with more symptoms. Specifically, we predicted a positive correlation between 'coping' reasons for use (i.e. the use of substances to cope with or alleviate negative affective states and positive symptoms) and both positive and general symptoms (as measured by the Positive and Negative Syndrome Scales (PANSS; Kay, Fiszbein, \& Opler, 1987).

\section{Method}

\subsection{Participants}

A total of 230 participants took part in the study. The majority of participants $(N=195)$ were taking part in a randomized controlled trial involving patients with psychosis and substance use disorder (The MIDAS trial: Motivational Interventions for Drugs \& Alcohol misuse in Schizophrenia. http://www.midastrial.ac.uk), 82 completed the questionnaire as part of their baseline assessment and an additional 113 completed it as part of their 12 month follow up. The remaining 35 participants had taken part in the $Q$ methodology study conducted by Gregg, Haddock, and Barrowclough (2009). Both studies recruited participants from community mental health teams and assertive outreach teams in four mental health trusts in Greater Manchester, UK. Participants were included if they met DSM IV diagnostic criteria for schizophrenia or another psychotic disorder combined with either substance abuse or dependence, or alcohol abuse or dependence (SCID IV criteria, First, Spitzer, Gibbon, \& Williams, 2002) and met minimum criteria for current substance use (at least twice per week for at least half the weeks in the preceding twelve weeks). Ethical approval for the study was granted by the local research ethics committee and informed consent was obtained from all participants.

\subsection{Procedure and measures}

The original $Q$ sample of 58 items was taken from a pool of 75 items derived from the existing self report literature; tape recordings of therapy sessions with 30 people involved in the MIDAS trial and from semi structured interviews with 10 people with a diagnosis of schizophrenia and comorbid substance use (see Gregg, Haddock, \& Barrowclough, 2009 for details). The $Q$ sort items that were identified as 'applying least' to the study participants (those positioned in 
columns $-5,-4,-3,-2$ of the $Q$ sort grid, See Fig. 1$)$ were identified and as a result 12 items were excluded. The final 46 items were assessed for similitude by 10 mental health professionals ( 6 research and 4 clinical psychologists) and a further 6 items were excluded (see Appendix A). The final questionnaire therefore consisted of 40 items describing situations in which people drink alcohol or use drugs. These were randomly ordered. Participants were asked to indicate whether they used their 'most problematic substance' (generally the substance that they used most often) in each situation "never", "sometimes", "often" or "almost always".

\subsubsection{Psychopathology}

The Positive and Negative Syndrome Scale (PANSS) was used to assess symptom severity. The PANSS is a 30 item structured clinical interview which is used to assess severity of positive symptoms, negative symptoms and general psychopathology in schizophrenia. Items are rated on 7-point Likert scales ( 0 absent-7 severe) which can be summed to provide a total severity score. The psychotic symptom rating scales (PSYRATS, Haddock, McCarron, Tarrier, \& Faragher, 1999) were used to assess auditory hallucinations and delusions. The PSYRATS includes items on the intensity and amount of distress caused by these symptoms. High PSYRATS scores indicate more severe and less controllable symptoms. The Global Assessment of Functioning (GAF) scale was used to rate the social, occupational and psychological functioning of participants. Depression was assessed using the Calgary depression scale (CDSS, Addington, Addington, \& Schissel, 1990) an interview which assesses depressive symptoms separate from positive, negative and extrapyramidal symptoms in people with schizophrenia. As part of this interview participants were also asked whether they had attempted suicide in the previous 12 months.

\subsubsection{Substance use}

The structured clinical interview (SCID-IV) substance use disorders module was used to differentiate substance abuse and dependence disorders. Data on current substance use behaviour (type and frequency of use over the preceding month) was collected using the timeline follow back interview (TLFB, Sobell and Sobell, 1992) and perceived consequences of substance use were assessed using the Inventory of Drug Use Consequences (InDUC, Blanchard, Morgerstern, Morgan, Labouvie, \& Bux, 2003). Motivational readiness to change was assessed using the Readiness to Change Questionnaire (RTCQ, Rollnick, Heather, Gold, \& Hall, 1992).

\subsection{Data analysis}

Data were analysed in two stages. First we conducted principal components analysis to examine the structure of the ReSUS scale and to develop subscales for use in subsequent analyses. Second we explored the relationship of the ReSUS subscales to demographic variables; psychiatric symptomatology, substance use, and readiness to change using multivariate analysis of variance (MANOVA) where data were categorical and Pearson correlations where data were continuous. Data on psychiatric symptomatology, readiness to change and extent of substance use (as determined by the TLFB and InDUC) were not available for the 35 participants who had taken part in the earlier $Q$ study. Where data were missing, all available data were analysed and the sample size for each analysis is reported in the text or in the tables.

\section{Results}

\subsection{Participant characteristics}

The sample consisted of 205 (89.1\%) males and 25 (10.9\%) females with a mean age of 37.3 years $(S D=9.5)$. The majority $(195,84.8 \%)$ described themselves as white and most were unemployed (221, $96.1 \%)$. Two out of five $(99,43.1 \%)$ were living alone at the time of the assessments, one third $(76,33 \%)$ were living with a partner or other family members and the remainder $(55,23.9 \%)$ were living in shared accommodation (including hostels) with non family members. The average age at which participants left full time education was 16 $(\mathrm{SD}=1.7)$.

The majority of participants (197, 85.7\%) had a diagnosis of schizophrenia. Other diagnoses included schizoaffective disorder $(14,6.1 \%)$, drug induced psychosis (7, 3.0\%), psychosis not otherwise specified (7, 3.0\%), delusional disorder (3,1.3\%) and schizophreniform disorder (2, $0.9 \%)$. Average illness duration was 11.9 years (SD 8.8).

On average, participants had been using their 'most problematic substance' (MPS) for 13.1 years ( $S D=8.9)$. Three quarters $(175,76.1 \%)$ met DSM IV criteria for substance use dependence whilst one quarter $(55,23.9 \%)$ met criteria for substance abuse. For half $(120,52.2 \%)$ the MPS was alcohol. Cannabis was the MPS for just under a third (68, $29.6 \%)$, followed by amphetamine (20, $8.7 \%)$, crack cocaine $(10,4.3 \%)$, heroin $(6,2.6 \%)$, cocaine $(5,2.2 \%)$ and ecstasy $(1,0.4 \%)$. On average, participants had used their MPS on 19 days of the previous 30 days $(S D=10.5)$. Over half $(113,58.2 \%)$ were poly substance users.

\subsection{Most frequently endorsed reasons for use}

On average, participants endorsed 24 reasons for use on the ReSUS (SD 8.4, range 4-38). The most frequently reported reasons for use (those items endorsed as being a reason for drinking/drug taking at least 'sometimes') were "When I want to chill out or relax" (217, 94.3\%), "When I am feeling stressed" (208, 90.4\%) and "When I am bored and want something to do to pass the time" (206, 89.6\%). One half of all participants (50.9\%) were using drugs or alcohol to cope with or reduce auditory hallucinations. Slightly more (57.4\%) were using substances to abate feelings of suspiciousness or paranoia and two out of five (38.7\%) were using substances when they were experiencing medication side effects. Frequency counts and percentages for each ReSUS item are given in Table 1.

\subsection{Principal components analysis}

The Kaiser-Meyer-Olkin (KMO) measure of sampling adequacy was .88 suggesting that the correlation patterns were compact and that a factor analysis should produce distinct and reliable factors (Field, 2005). Principal components analysis with oblique (direct oblimin) rotation initially resulted in ten components with eigenvalues greater than one. The Scree plot indicated that three of these components should be retained. The three component solution accounted for $41 \%$ of the variance. Two of the forty items did not load on any of the three components $(\leq 0.30)$ however and the analysis was therefore repeated with these two items excluded. The final three component solution explained $42 \%$ of the variance. Eighteen items loaded on the first component, 11 loaded on the second and 9 loaded on the third. (See Table 2 for component loadings). Component 1 , labeled 'coping with distressing emotions and symptoms' consisted of all of the items relating to negative affective states and to psychiatric symptoms. Components 2 and 3 both contained items related to the improvement of positive affective states, but component 2, labeled 'social enhancement and intoxication', also contained items related to social acceptance e.g. 'when I am with friends and we want to have a good time', 'when I want to fit in' and 'when I am under pressure from others' and intoxication 'when I want to feel drunk, stoned or high'. Component 3, labeled 'individual enhancement', contained items that were more related to the improvement of internal emotional and physical states (e.g. 'when I want to feel more creative', 'when I want to feel sexy' and 'when I am experiencing medication side effects'). The average score for each subscale was used as the subscale score in subsequent analyses. 
Table 1

Most frequently endorsed reasons for use.

\begin{tabular}{|c|c|c|}
\hline ReSUS item & Frequency & $\%$ \\
\hline When I want to chill out or relax & 217 & 94.3 \\
\hline When I am feeling stressed & 208 & 90.4 \\
\hline When I am bored and want something to do to pass the time & 206 & 89.6 \\
\hline When I want to feel good, have a laugh or be happier & 203 & 88.3 \\
\hline When I am with friends and we want to have a good time & 194 & 84.3 \\
\hline When I want to escape from my problems and worries & 194 & 84.3 \\
\hline When I feel anxious or tense & 191 & 83.0 \\
\hline When I am feeling lonely & 181 & 78.7 \\
\hline When I am feeling depressed & 179 & 77.8 \\
\hline When I want to feel drunk, stoned or high & 177 & 77.0 \\
\hline When I am feeling happy and content with my life & 176 & 76.5 \\
\hline When I want to 'feel different' or alter my state of mind & 165 & 71.7 \\
\hline When my thoughts are racing & 163 & 70.9 \\
\hline When I have trouble sleeping & 160 & 69.6 \\
\hline When I feel excited about something & 160 & 69.6 \\
\hline $\begin{array}{l}\text { When I am thinking about bad things that have happened } \\
\text { to me in the past }\end{array}$ & 158 & 68.7 \\
\hline When I want to feel more confident & 157 & 68.3 \\
\hline When I am experiencing unpleasant thoughts & 156 & 67.8 \\
\hline When I think about how good it tastes & 151 & 65.7 \\
\hline When I am angry at the way things have turned out & 146 & 63.5 \\
\hline When I want to feel normal & 144 & 62.6 \\
\hline $\begin{array}{l}\text { When I feel under pressure from other people to } \\
\text { use drugs/drink alcohol }\end{array}$ & 142 & 61.7 \\
\hline When I want to fit in with other people & 135 & 58.7 \\
\hline When I am having trouble communicating with others & 134 & 58.3 \\
\hline When I am feeling suspicious or paranoid & 132 & 57.4 \\
\hline When I am having trouble thinking or concentrating & 132 & 57.4 \\
\hline When I want to feel more self aware & 126 & 54.8 \\
\hline When I start to feel guilty about something & 124 & 53.9 \\
\hline When I want to feel more creative & 122 & 53.0 \\
\hline When I am feeling ashamed or bad about myself & 118 & 51.3 \\
\hline When I am hearing sounds or voices that other people can't hear & 117 & 50.9 \\
\hline When I need motivation to do things & 113 & 49.1 \\
\hline When I want to stay awake, be more alert or energetic & 111 & 48.3 \\
\hline When I unexpectedly find some drugs/alcohol & 108 & 47.0 \\
\hline When I want to feel more emotions & 106 & 46.1 \\
\hline When I feel I have been discriminated against & 100 & 43.5 \\
\hline When I am in pain & 100 & 43.5 \\
\hline $\begin{array}{l}\text { When I have been drinking and think about using } \\
\text { drugs (or vice versa) }\end{array}$ & 97 & 42.2 \\
\hline When I am experiencing medication side effects & 89 & 38.7 \\
\hline When I want to feel sexy or increase my sexual enjoyment & 82 & 35.7 \\
\hline
\end{tabular}

Internal consistency of the three subscales was good. Cronbach's alpha for the 'coping' subscale was $.91 ; .81$ for 'social enhancement' and .82 for 'individual enhancement'. Alphas would not have been improved by the deletion of any items. Item-total correlations were also good ranging from .42 to .70 for 'coping', .40 to .60 for 'social enhancement' and .40 to .68 for 'individual enhancement'. Twenty five participants completed the measure on a second occasion four weeks after completing it for the first time in order to assess testretest reliability. The pairs of scores for the three subscales were significantly correlated ( $r=.68, .87$ and .76 respectively) and paired samples $t$ tests showed that the total scores for each subscale did not significantly differ between the two time points $(p=.53, .61$, and .73 respectively).

We compared ReSUS subscale scores for those participants who had completed the assessments at baseline $(N=117)$ to those who had completed them at follow up $(N=113)$ and found no significant differences.

\subsection{Relationship of ReSUS subscales to demographic variables}

There were no significant relationships between the three ReSUS subscales and gender, age, racial origin or employment status (see Tables 3 and 4). There was a main effect for 'living arrangements' but univariate tests showed that there were no significant differences between the three groups, other than a trend for participants who lived in house shares or in a hostel accommodation to be more likely to report using substances for 'individual enhancement' purposes $(F(2,227)=2.81, p=.062)$. The longer participants had stayed in full time education the less likely they were to report using substances for 'coping' ( $r=-217, p=.003)$ and 'individual enhancement' reasons $(r=-.161, p=.026)$.

\subsection{Relationship of ReSUS subscales to psychiatric history and symptomatology}

DSM IV diagnosis was not associated with subscale scores and nor was illness duration. As predicted, scores on the 'coping' subscale of the ReSUS were significantly associated with the majority of psychopathology measures: there were positive correlations between 'coping with distressing emotions and symptoms' and PANSS total scores; PANSS general symptoms; PANSS positive symptoms; PYRATS hallucinations; PSYRATS delusions and Calgary depression (see Table 4 for Pearson correlation coefficients). Global assessment of functioning (GAF) scores were also negatively correlated with this subscale. Suicide behavior (at least one attempt in the previous 12 months) was also associated with 'coping' reasons for use.

Table 2

Pattern matrix.

\begin{tabular}{|c|c|c|c|}
\hline \multicolumn{4}{|l|}{ Coping with distressing emotions and symptoms } \\
\hline When I am experiencing unpleasant thoughts & .814 & & \\
\hline When I feel ashamed or bad about myself & .782 & & \\
\hline $\begin{array}{l}\text { When I am thinking about bad things that have } \\
\text { happened in the past }\end{array}$ & .715 & & \\
\hline When my thoughts are racing & .703 & & \\
\hline When I want to escape from my problems and worries & .679 & & \\
\hline When I am feeling suspicious or paranoid & .677 & & \\
\hline When I am feeling depressed & .675 & & \\
\hline When I am angry at the way things have turned out & .671 & & \\
\hline When I feel anxious or tense & .651 & & \\
\hline When I start to feel guilty about something & .586 & & \\
\hline When I am feeling stressed & .582 & & \\
\hline When I am having trouble sleeping & .543 & .342 & \\
\hline When I feel I have been discriminated against & .528 & & \\
\hline $\begin{array}{l}\text { When I am hearing sounds or voices that } \\
\text { other people can't hear }\end{array}$ & .516 & & \\
\hline When I am having trouble thinking or concentrating & .498 & & \\
\hline When I am having trouble communicating with others & .472 & & \\
\hline When I am in pain physically & .452 & & \\
\hline When I am feeling lonely & .431 & & \\
\hline \multicolumn{4}{|l|}{ Social enhancement \& intoxication } \\
\hline When I am feeling happy and content with my life & & .744 & \\
\hline When I want to feel good, have a laugh or be happier & & .669 & \\
\hline When I am with friends and we want to have a good time & & .659 & \\
\hline When I want to chill out or relax & & .563 & \\
\hline When I think about how good it tastes & & .545 & \\
\hline When I feel excited about something & & .505 & \\
\hline When I want to fit in with other people & & .454 & \\
\hline When I want to feel drunk, stoned or high & & .370 & \\
\hline $\begin{array}{l}\text { When I feel under pressure from others to } \\
\text { use drugs/drink alcohol }\end{array}$ & & .367 & \\
\hline $\begin{array}{l}\text { When I have been drinking and think about } \\
\text { using drugs (or vice versa) }\end{array}$ & & .343 & \\
\hline When I am bored and want something to do to pass the time & & .341 & \\
\hline \multicolumn{4}{|l|}{ Individual enhancement } \\
\hline When I want to feel more self aware & & & .758 \\
\hline When I need motivation to do things & & & .722 \\
\hline When I want to stay awake or be more alert & & & .716 \\
\hline When I want to feel more creative & & & .645 \\
\hline When I want to feel more emotions & & & .550 \\
\hline When I want to feel sexy & & & .475 \\
\hline When I am experiencing medication side effects & & & .442 \\
\hline When I want to feel normal & & & .439 \\
\hline When I want to feel more confident & & .304 & .425 \\
\hline$\%$ variance explained & 27.7 & 9.1 & 5.1 \\
\hline Cronbach's alpha & .91 & .81 & .82 \\
\hline Mean score (SD) & $\begin{array}{l}1.11 \\
(.64)\end{array}$ & $\begin{array}{l}1.32 \\
(.58)\end{array}$ & $\begin{array}{l}0.82 \\
(.62)\end{array}$ \\
\hline
\end{tabular}


Table 3

Mean differences in ReSUS subscale scores.

\begin{tabular}{|c|c|c|c|c|c|}
\hline & & Subscale 1 'coping' & Subscale 2 'social enhancement' & Subscale 3 'individual enhancement' & Wilk's lambda \\
\hline & $N$ & Mean (SD) & Mean (SD) & Mean (SD) & $F(p)$ \\
\hline \multicolumn{6}{|l|}{ Gender } \\
\hline Male & 205 & $1.11(.65)$ & $1.33(.59)$ & $.84(.63)$ & \multirow[t]{2}{*}{$1.15(.330)$} \\
\hline Female & 25 & $1.08(.55)$ & $1.24(.47)$ & $.62(.49)$ & \\
\hline \multicolumn{6}{|l|}{ Racial origin } \\
\hline White & 195 & $1.13(.65)$ & $1.32(.56)$ & $.81(.62)$ & \multirow[t]{2}{*}{$1.14(.333)$} \\
\hline Non-white & 35 & $.98(.50)$ & $1.37(.67)$ & $.85(.63)$ & \\
\hline \multicolumn{6}{|l|}{ Living arrangements } \\
\hline Alone & 99 & $1.05(.59)$ & $1.30(.54)$ & $.74(.51)$ & \multirow[t]{3}{*}{$2.48(.022)$} \\
\hline With partner/family & 76 & $1.21(.69)$ & $1.38(.62)$ & $.80(.71)$ & \\
\hline Shared/hostel & 55 & $1.07(.64)$ & $1.31(.61)$ & $.98(.64)$ & \\
\hline \multicolumn{6}{|l|}{ Employment status } \\
\hline Unemployed & 221 & $1.11(.64)$ & $1.33(.59)$ & $.82(.62)$ & \multirow[t]{2}{*}{$.03(.993)$} \\
\hline Employed & 9 & $1.12(.45)$ & $1.30(.44)$ & $.85(.59)$ & \\
\hline \multicolumn{6}{|l|}{ DSM IV diagnosis } \\
\hline Schizophrenia & 197 & $1.10(.63)$ & $1.36(.58)$ & $.84(.62)$ & \multirow[t]{6}{*}{$.96(.809)$} \\
\hline Schizoaffective disorder & 14 & $1.22(.64)$ & $1.11(.58)$ & $.68(.63)$ & \\
\hline Schizophreniform disorder & 2 & $.81(.51)$ & $1.23(.71)$ & $.44(.47)$ & \\
\hline Delusional disorder & 3 & $1.01(.39)$ & $1.12(.67)$ & $.63(.63)$ & \\
\hline Drug induced psychosis & 7 & $1.12(.75)$ & $1.14(.67)$ & $.82(.81)$ & \\
\hline Psychosis NOS & 7 & $1.10(79)$ & $1.06(.35)$ & $.54(.63)$ & \\
\hline \multicolumn{6}{|l|}{ Suicide behavior } \\
\hline At least one attempt & 31 & $1.42(.50)$ & $1.22(.43)$ & $.86(.53)$ & \multirow[t]{2}{*}{$4.60(.004)$} \\
\hline No suicide behavior & 157 & $1.06(.68)$ & $1.31(.62)$ & $.82(.67)$ & \\
\hline \multicolumn{6}{|l|}{ DSM substance use } \\
\hline Abuse & 37 & $.84(.59)$ & $1.21(.62)$ & $.75(.64)$ & \multirow[t]{2}{*}{$3.04(.030)$} \\
\hline Dependence & 158 & $1.18(.66)$ & $1.32(.58)$ & $.84(.63)$ & \\
\hline \multicolumn{6}{|l|}{ Most problematic substance } \\
\hline Alcohol & 120 & $1.09(.65)$ & $1.26(.59)$ & $.72(.56)$ & \multirow[t]{7}{*}{$1.84(.018)$} \\
\hline Cannabis & 68 & $1.05(.58)$ & $1.42(.61)$ & $.78(.61)$ & \\
\hline Amphetamines & 20 & $1.22(.59)$ & $1.33(.49)$ & $1.20(.73)$ & \\
\hline Crack cocaine & 10 & $1.36(.82)$ & $1.55(.82)$ & $1.27(.84)$ & \\
\hline Cocaine & 5 & $.89(.87)$ & $1.02(.28)$ & $.87(.58)$ & \\
\hline Heroin & 6 & $1.38(.51)$ & $1.32(.32)$ & $1.11(.44)$ & \\
\hline Ecstasy & 1 & 1.22 & 1.00 & 1.11 & \\
\hline \multicolumn{6}{|l|}{ Readiness to Change } \\
\hline Precontemplation & 51 & $.85(.66)$ & $1.21(.66)$ & $.76(.67)$ & \multirow[t]{3}{*}{$3.80(.001)$} \\
\hline Contemplation & 77 & $1.30(.64)$ & $1.36(.54)$ & $.80(.62)$ & \\
\hline Action & 64 & $1.12(.61)$ & $1.33(.59)$ & $.91(.63)$ & \\
\hline
\end{tabular}

Participants who had previously attempted suicide were more likely to be using substances as an attempt to cope with distressing emotions and symptoms $(F(1,185)=7.9, p=.005)$.
The 'individual enhancement' scale of the ReSUS was positively correlated with PANSS total scores, PANSS positive symptoms. PSYRATS hallucinations and negatively correlated with GAF symptom

Table 4

Associations between ReSUS subscale scores and continuous demographic, psychopathology and substance use variables.

\begin{tabular}{|c|c|c|c|c|}
\hline & $N$ & Subscale 1 'coping' & Subscale 2 'social enhancement' & Subscale 3 'individual enhancement' \\
\hline Age & 230 & .004 & -.071 & .030 \\
\hline Years in full time education & 191 & $-.217^{* *}$ & -.123 & $-.161^{*}$ \\
\hline Illness duration & 193 & .079 & -.021 & .115 \\
\hline PANSS total & 193 & $.269^{* *}$ & -.009 & $.152^{*}$ \\
\hline PANSS positive & 193 & $.209^{* *}$ & .040 & $.187^{* *}$ \\
\hline PANSS negative & 193 & .114 & -.024 & .126 \\
\hline PANSS general & 193 & $.279^{* *}$ & -.030 & .074 \\
\hline Psyrats delusions & 195 & $.264^{* *}$ & .057 & .105 \\
\hline Psyrats hallucinations & 188 & $.259^{* *}$ & .057 & $.157^{*}$ \\
\hline GAF symptoms & 190 & $-.289^{* *}$ & -.067 & $-.162^{*}$ \\
\hline GAF disability & 190 & $-.185^{*}$ & .002 & -.090 \\
\hline GAF total & 190 & $-.272^{* *}$ & -.069 & $-.191^{* *}$ \\
\hline Calgary depression & 192 & $.339^{* *}$ & -.050 & .055 \\
\hline Years of substance use & 187 & .045 & .009 & .121 \\
\hline Days abstinent from MPS & 192 & -.005 & .054 & .097 \\
\hline Cost of MPS (drugs only) & 86 & $.215^{*}$ & .117 & .150 \\
\hline Units of alcohol & 106 & .150 & .104 & .131 \\
\hline \multicolumn{5}{|l|}{ In DUC consequences } \\
\hline Physical & 193 & $.496^{* *}$ & $.256^{* *}$ & $.232^{* *}$ \\
\hline Intrapersonal & 192 & $.493^{* *}$ & $.193^{* *}$ & $.200^{* *}$ \\
\hline Social responsibility & 193 & $.406^{* *}$ & $.291^{* *}$ & $.257^{* *}$ \\
\hline Interpersonal & 192 & $.387^{* *}$ & $.179^{*}$ & $.261^{* *}$ \\
\hline Impulse control & 192 & $.452^{* *}$ & $.251^{* *}$ & $286^{* *}$ \\
\hline
\end{tabular}

*Pearson correlation coefficient significant at $p<0.05 ;{ }^{* *}$ Significant at $p<0.01$. 
and total scores (Table 4). The 'social enhancement' subscale was not related to any psychopathology variables.

\subsection{Relationship of ReSUS subscales to type and level of substance use}

Years of substance use were not related to the ReSUS subscales. Participants who met criteria for substance use dependence scored more highly on the 'coping' subscale than those who met criteria for abuse. There was also a significant main effect for drug type. Univariate tests showed that participants who were using amphetamines, crack cocaine and heroin were more likely to report using them for 'individual enhancement' reasons than those who were using other substances $(F(6,223)=3.13, p=.006)$.

There was a significant association between scores on the 'coping' subscale and the amount of money spent on the most problematically used substance over the previous 30 days (where the MPS was a drug) but not with the numbers of days abstinent from substance use suggesting that those who were using for coping reasons were not using their MPS more frequently but may well have been using it in greater amounts when they did. There were no relationships between the units of alcohol used by those whose MPS was alcohol and the ReSUS subscales.

Multivariate analysis revealed a significant main effect for motivation to change. Univariate tests showed that participants who were currently contemplating reducing their drug or alcohol use were more likely to be using substances for 'coping' reasons than those who were not considering making any such changes $(F(2,189)=7.8$, $p=.001$ ).

The negative consequences of substance use (physical, intrapersonal, social, interpersonal and impulse control) were significantly correlated with all three subscale scores: higher ReSUS scores were related to more negative consequences. The 'social enhancement' and 'individual enhancement' subscales were not related to any other substance use variables.

\section{Discussion}

The ReSUS is a valid and reliable measure for assessing reasons for substance use in people with schizophrenia and other psychotic disorders. Each of items in the ReSUS questionnaire was endorsed by at least a third of participants confirming the relevance of the scale's items for people with psychosis and the three subscales demonstrated good levels of internal consistency and stability over time. Analyses examining associations between the ReSUS subscales, psychopathology and substance use also provided support for the validity of the measure. As predicted, the three subscales were broadly in line with the three factors identified by Gregg, Haddock, and Barrowclough (2009): the first subscale contained items related to distressing emotions and symptoms (including feelings of shame, boredom and depression), the second consisted of items related to social acceptance and enhancement (to fit in, feel good and get high) and the third contained items that were related to the improvement of internal emotional and physical states (to feel sexy, creative and confident). The most frequently endorsed reasons for use: "when I want to chill out or relax", "when I am feeling stressed", "when I am bored and want something to do to pass the time" and "when I want to feel good, have a laugh or be happier" were broadly similar to those reported by the earlier self report studies (e.g. Addington \& Duchak, 1997; Baker et al., 2002; Dixon, Haas, Weiden, \& Frances, 1991; Fowler, Carr, Carter, \& Lewin, 1998; Gregg, Haddock, \& Barrowclough, 2009; Schofield et al., 2006; Spencer, Castle, \& Michie, 2002). Significantly, more than half of all participants were using drugs or alcohol to cope with or reduce auditory hallucinations, or abate feelings of suspiciousness or paranoia at least some of the time and two out of five reported using substances when they were experiencing medication side effects, figures higher than those reported by
Gregg, Haddock, and Barrowclough (2009) and elsewhere in the literature (see Gregg, Barrowclough, \& Haddock, 2007 for a review). These high rates of 'self medication' may be partly attributable to the homogenous nature of our sample. In contrast to some of the earlier studies all of our study participants met DSM IV criteria for a psychotic disorder and all had a current substance abuse or dependence disorder.

In contrast to our predictions and the findings of Gregg, Haddock, and Barrowclough (2009), ReSUS subscale scores did not vary according to gender. Although the men in our sample had slightly higher mean scores on each of the three subscales this difference was not statistically significant. However, we must also note that there were just 25 women in the sample, and it could well be the case that a sample with a higher proportion of women may have found a difference. Similarly there were very few employed people in the study and just $15 \%$ were 'non-white' making comparisons involving these underrepresented groups difficult. Just one demographic variable was associated with reasons for use: participants who had spent longer in full time education were less likely to report using substance for either 'coping' or 'individual enhancement' purposes.

We anticipated that reasons for use would be related to both quantity of substance use, with higher scores on the ReSUS subscales being associated with higher quantities of use and with problems associated with substance use, with higher ReSUS scores being associated with more self reported negative consequences. The results only partially supported our hypotheses: there was no association between ReSUS subscales and frequency of substance use i.e. the number of days abstinent from substance use according to the timeline followback. Nor was there a significant relationship between ReSUS subscales and the units of alcohol consumed by those people for whom the 'most problematic substance' (MPS) was alcohol. There was however a significant correlation between the 'coping' subscale of the ReSUS and the cost of the MPS where the MPS was a drug indicating that participants who used drugs for this reason were using in higher quantities. People who used substances for coping reasons also reported greater negative consequences as a result of that use. These findings provide support for Spencer, Castle, and Michie (2002) who found that 'coping with unpleasant affect' significantly predicted quantity of recent use and problems related to that use. We also found evidence to support Spencer et al's assertion that people with psychosis who use substances to cope with unpleasant affect and positive symptoms are more likely to be psychologically dependent on those substances. Participants in our sample who met criteria for drug or alcohol dependence scored more highly on the coping subscale than those who met abuse criteria.

'Individual enhancement' reasons for use were related to the type of substance consumed (amphetamine, crack cocaine and heroin users were more likely to report using for these reasons) and to greater negative consequences but were not related to either the frequency or quantity of drugs or alcohol consumed. Likewise 'social enhancement' reasons for use were related to negative consequences of substance use but not to type, frequency or quantity of substance use.

We expected that reasons for use would be related to psychiatric symptomatology with higher ReSUS scores being associated with more symptoms and predicted a positive correlation between 'coping' reasons for use and both positive and general symptoms. Our hypotheses were partially supported. 'Coping with distressing emotions and symptoms' was positively correlated with PANSS total, positive and general symptom scores. Additionally, coping reasons for use were related to PSYRATS hallucinations and delusions; GAF symptoms and disability; depression and suicide behaviour indicating that participants who were experiencing the most symptoms and experiencing the highest levels of distress were more likely to be using substances in an attempt to alleviate or cope with those symptoms. 
The individual enhancement subscale was associated with greater positive symptoms (reflected in higher PANSS total and positive symptom scores and PSYRATS hallucinations scores) and with decreased functioning but the social enhancement subscale was not related to any psychopathology measures.

It is interesting to note that participants using substances for 'coping' reasons were more likely to be contemplating reducing their drug or alcohol use. As coping reasons for use were also related to both greater psychiatric symptomatology and greater negative consequences resulting from substance use it is possible that this relationship stems from an understanding that substance use is no longer having the desired effect. As Addington and Duchak (1997) and Dixon et al. (1991) found, some people may report using drugs and alcohol to make them feel better yet report feeling worse afterwards.

That the coping subscale showed the greatest number of associations with psychopathology and substance use variables is significant. Research has shown that people with schizophrenia may possess a relatively limited repertoire of coping strategies (Rollins, Bond, \& Lysaker, 1999) and that they employ a range of cognitive and behavioural strategies in an attempt to control or cope with their symptoms (e.g. Falloon \& Talbot, 1981; Lobban, Barrowclough, \& Jones, 2004) thus it may be the case that substances are being used by people with psychosis as a general coping mechanism to cope with the symptoms of schizophrenia and with the negative affective experiences associated with a diagnosis of schizophrenia. Our results would certainly seem to indicate that this is the case. If the direction of these hypothesized relationships were confirmed in future research it would provide supportive evidence for the utility of cognitive behavioural treatment approaches in reducing substance use in people with psychosis.

\subsection{Limitations and suggestions for further research}

The study has several limitations. The sample was overwhelmingly male, white and unemployed making our comparisons of gender, racial origin and employment status difficult to draw conclusions from. We did not record the socioeconomic status of participants and could not make comparisons on this basis. Future research should seek to ensure that all demographic sub groups are adequately represented so that comparisons between groups can be made. The majority of participants were alcohol and cannabis users and comparatively few were using different classes of substances. Future research should also seek to ensure that adequate numbers of users of each type of substance are represented so that comparisons between substance types can be made. Significantly, although more than half of the sample was using more than one substance we only examined reasons for use for the MPS, we were therefore unable to fully assess whether different substances were used for different reasons. Our between subjects analysis appeared to suggest that alcohol and cannabis were used for similar reasons but that other classes of drugs (stimulants and opiates) were more likely to be used for individual enhancement purposes. It would have been interesting to examine whether individual participants were selecting specific substances for specific reasons as Khantzian (1985) proposed.

Despite these limitations we were able to demonstrate the reliability and validity of the ReSUS scale, a scale which could be usefully employed as both a research instrument and a therapeutic tool in order to help clients describe their drug and alcohol use. Future research with the ReSUS should explore the observed relationships further, in particular the association between 'coping' reasons for use, symptoms and substance use variables and seek to disentangle the direction of these relationships, ideally in longitudinal studies. A fuller understanding of these relationships could inform the development and selection of treatments aimed at reducing substance use by people with psychosis.

\section{Appendix A}

\section{Excluded items}

\begin{tabular}{ll}
\hline $\begin{array}{l}\text { Reason } \\
\text { Infrequent }\end{array}$ & When I want to lose weight \\
endorsement & When I want to experience more voices \\
When I want to think more, or increase the number \\
of thoughts I am having \\
When I want to work and study better \\
When I am using other drugs and want to enhance \\
their effects or 'come down' \\
When I want to increase my appetite \\
When I want to see whether I can take drugs in moderation \\
When other people reject me or don't seem to like me \\
When I feel that my family is putting a lot of pressure on me or that I \\
don't measure up to their expectations \\
When I am not getting along well with others at school or at work \\
When there are arguments or fights at home \\
When I feel that someone is trying to control me and \\
I want to feel more independent \\
When I feel confident and relaxed \\
When I feel tense or uneasy in the presence of someone \\
When I have something to celebrate \\
When I feel I need courage to face up to people socially \\
Wher PCA
\end{tabular}

\section{References}

Addington, J., \& Duchak, V. (1997). Reasons for substance use in schizophrenia. Acto Psychiatrica Scandivica, 96, 329-333.

Addington, D., Addington, J., \& Schissel, B. (1990). A depression rating scale for schizophrenics. Schizophrenia Research, 3, 247-251.

Baker, A., Lewin, T., Reichler, H., Clancy, R., Carr, V., Garrett, R., et al. (2002). Motivational interviewing among psychiatric in-patients with substance use disorders. Acto Psychiatrica Scandinavica, 106, 233-240.

Blanchard, K. A., Morgerstern, J., Morgan, T. J., Labouvie, E. W., \& Bux, D. A. (2003). Assessing consequences of substance use: psychometric properties of the inventory of drug use consequences. Psychology of Addictive Behaviours, 17, 328-331.

Cuffel, B. J., Shumway, M., Choulgian, T. L., \& MacDonald, T. (1994). A longitudinal study of substance use and community violence in schizophrenia. Journal of Nervous and Mental Disease, 182, 704-708.

Dixon, L., Haas, G. H., Weiden, P. J., \& Frances, A. J. (1991). Drug abuse in schizophrenic patients: Clinical correlates and reasons for use. American Journal of Psychiatry, 148 224-230.

Drake, R. E., Osher, F. C., \& Wallach, M. A. (1989). Alcohol use and abuse in schizophrenia: A prospective community study. Journal of Nervous and Mental Disease, $177,408-414$

Drake, R. E., Osher, F. C., \& Wallach, M. A. (1991). Homelessness and dual diagnosis. American Psychologist, 46, 1149-1158.

Falloon, I. R. H., \& Talbot, R. E. (1981). Persistent auditory hallucinations: Coping mechanisms and implications for management. Psychological Medicine, 11, $329-339$.

Field, A. (2005). Discovering statistics using SPSS. London: SAGE.

First, M. B., Spitzer, R. L., Gibbon, M., \& Williams, J. B. W. (2002). Structured Clinical Interview for DSM-IV-TR Axis I Disorders, Research Version, Patient edition. (SCIDI/P). Biometrics Research, New York State Psychiatric Institute.

Fowler, I. L., Carr, V. J., Carter, N. T., \& Lewin, T. J. (1998). Patterns of current and lifetime substance use in schizophrenia. Schizophrenia Bulletin, 24, 443-455.

Gearon, J. S., Bellack, A. S., Rachbeisel, J., \& Dixon, L. (2001). Drug-use behavior and correlates in people with schizophrenia. Addictive Behaviors, 26, 51-61.

Goswami, S., Mattoo, S. K., Basu, D., \& Singh, G. (2004). Substance-abusing schizophrenics: Do they self-medicate? The American Journal on Addictions, 13, 139-150

Green, B., Kavanagh, D. J., \& Young, R. M. C. D. (2004). Reasons for cannabis use in men with and without psychosis. Drug and Alcohol Review, 23, 445-453.

Gregg, L., Barrowclough, C., \& Haddock, C. (2007). Reasons for increased substance use in psychosis. Clinical Psychology Review, 27, 494-510.

Gregg, L., Haddock, G., \& Barrowclough, C. (2009). Self reported reasons for substance use in Schizophrenia: A Q methodological investigation. Mental Health and Substance Use: dual diagnosis, 2, 24-39.

Haddock, G., McCarron, J., Tarrier, N., \& Faragher, B. (1999). Scales to measure dimensions of hallucinations and delusions: The psychotic rating scales (PSYRATS) Psychological Medicine, 29, 879-889.

Kay, S., Fiszbein, A., \& Opler, L. (1987). The positive and negative syndrome scales (PANSS) for schizophrenia. Schizophrenia Bulletin, 13, 261-275.

Khantzian, E. J. (1985). The self-medication hypothesis of addictive disorders: Focus on heroin and cocaine dependence. American Journal of Psychiatry, 142, 1259-1264. 
Khantzian, E. J. (1997). The self-medication hypothesis of substance use disorders: A reconsideration and recent applications. Harvard Review of Psychiatry, 4, 231-244.

Linszen, D. H., Dingemans, P. M., \& Lenior, M. E. (1994). Cannabis use and the course of recent onset schizophrenic disorders. Archives of General Psychiatry, 51, 273-279.

Lobban, F., Barrowclough, C., \& Jones, S. (2004). The impact of beliefs about mental health problems and coping on outcome in schizophrenia. Psychological Medicine, $34,1165-1176$.

Pencer, A., \& Addington, J. (2003). Substance use and cognition in early psychosis. Journal of Psychiatry and Neuroscience, 28, 48-54.

Regier, D. A., Farmer, M. F., Rae, D. S., Locke, B. Z., Keith, S. J., Judd, L. L., et al. (1990) Comorbidity of mental disorders with alcohol and other drug abuse: Results from the Epidemiologic Catchment Area (ECA) Study. JAMA, 264, 251-2518.

Rollins, A. L., Bond, G. R., \& Lysaker, P. H. (1999). Characteristics of coping with the symptoms of schizophrenia. Schizophrenia Research, 36, 30.
Rollnick, S., Heather, N., Gold, R., \& Hall, W. (1992). Development of a short 'readiness to change' questionnaire for use in brief, opportunistic interventions among excessive drinkers. British Journal of Addiction, 87, 743-754.

Schofield, D., Tennant, C., Nash, L., Degenhardt, L., Cornish, A., Hobbs, C., et al. (2006). Reasons for cannabis use in psychosis. Australian and New Zealand Journal of Psychiatry, 40, 570-574.

Sobell, L. C., \& Sobell, M. B. (1992). Timeline follow-back: A technique for assessing selfreported alcohol consumption. In R. Litten \& J. Allen (Eds.), Measuring alcohol consumption (pp. 207-224). Rockville, MD: The Humana Press Inc.

Spencer, C., Castle, D., \& Michie, P. T. (2002). Motivations that maintain substance use among individuals with psychotic disorders. Schizophrenia Bulletin, 28, 233-247.

Stephenson, W. (1953). The study of behavior: Q-technique and its methodology. Chicago: University of Chicago Press. 